estudios 


\title{
El criollismo popular en Argentina, ¿hasta cuándo? Personajes, autores y editores de un fenómeno de literatura masiva
}

\author{
Popular criollismo in Argentina, for how long? Characters, \\ authors and publishers of a mass literary phenomenon \\ O crioulismo popular na Argentina até quando? Personagens, \\ autores e editores de um fenómeno de literatura massiva
}

\section{Ezequiel Adamovsky}

UNIVERSIDAD DE SAN MARTÍN - UNIVERSIDAD DE BUENOS AIRES / CONICET, ARGENTINA $\mathrm{PhD}$ in History, University College London. Principales publicaciones:

Euro-Orientalism: Liberal Ideology and the Image of Russia in France,

c. 1740-1880 (Peter Lang, 2006); Historia de la clase media argentina:

Apogeo y decadencia de una ilusión, 1919-2003 (Planeta, 2009); La marchita, el escudo y el bombo: una historia cultural de los emblemas del peronismo, de Perón a Cristina Kirchner (Planeta, 2016; en coautoría con Esteban Buch). Correo electrónico: e.adamovsky@gmail.com 


\section{Resumen}

En su estudio sobre la literatura criollista popular, Adolfo Prieto explicó su éxito a fines del siglo XIX como una expresión de las tensiones de la "modernización". Según esta interpretación, el fenómeno entró en una rápida extinción al comenzar la década de 1920. Analizando la circulación de ediciones baratas de las historias gauchescas y los perfiles y trayectorias de sus editores y autores, este artículo propone correr la fecha de desaparición del fenómeno en cuestión hacia comienzos de los años cincuenta. Hacia el final, se invita a considerar explicaciones alternativas de la popularidad del criollismo.

Palabras clave: criollismo; gaucho; literatura popular; Argentina

\section{Abstract}

In his study of the popular criollista literature, Adolfo Prieto explained its success in the late 19th century

as an expression of the tensions brought on by "modernization According to this interpretation, Prieto argued that the phenomenon quickly disappeared in the 1920s. By studying the circulation of cheap editions of gaucho stories, and the profiles and careers of publishers and authors, this article proposes to relocate the extinction of this phenomenon in the early $1950 \mathrm{~s}$. In the last paragraphs, it also invites to consider alternative explanations of the popularity of criollismo.

Keywords: criollismo; gaucho; popular literature; Argentina

\section{Resumo}

No seu estudo sobre a literatura crioulista popular, Adolfo Prieto explicou seu sucesso nos finais do século XIX como expressão das tensões da "modernização". Segundo esta interpretação, o fenómeno entrou numa rápida extinção ao começar a década de 1920. Analisando a circulação de edições baratas das histórias gauchescas e os perfis e trajetórias dos seus editores e autores, este artigo propõe mudar a data de desaparecimento do fenómeno em questão para começos dos anos cinquenta. Por fim, convida-se a considerar explicações alternativas da popularidade do crioulismo.

Palavras-chave: crioulismo; gaúcho; literatura popular; Argentina

RECIBIDO: 27 DE ENERO DE 2017. ACEPTADO: 28 DE ABRIL DE 2017. DISPONIBLE EN LÍNEA: 8 DE AGOSTO DE 2018

\section{Cómo citar este artículo:}

Adamovsky, Ezequiel. "El criollismo popular en Argentina, ¿'hasta cuándo? Personajes, autores y editores de un fenómeno de literatura masiva". Cuadernos de Literatura 22.43 (2018): 172-207. https://doi.org/10.11144/Javeriana.cl22-43.crpo 
LUEGO DE 1880 se difundió en Argentina un discurso "criollista" por el que la figura del gaucho se transformó en la encarnación por antonomasia del bajo pueblo y de lo genuinamente argentino. El criollismo se originó inicialmente como una literatura de consumo masivo y popular que narraba las desventuras de una serie de personajes gauchescos que resultarían enormemente exitosos. Esas historias, difundidas mediante impresos baratos y como folletines en los diarios, se reprodujeron muy pronto en otros formatos, especialmente en pantomimas y representaciones en el circo criollo, en los tablados de los teatros, en las canciones de los "payadores" de la época y en revistas populares que florecieron a partir de finales del siglo.

En su clásico estudio sobre este fenómeno, Adolfo Prieto explicó el éxito de esta literatura a partir de las funciones diferentes que desempeñó entre tres grupos sociales. Para la población nativa desplazada del campo hacia ciudades en rápido crecimiento, el criollismo pudo ser "una expresión de nostalgia o una forma sustitutiva de rebelión contra la extrañeza y las imposiciones del escenario urbano". En segundo lugar, imitar los estilos que el criollismo ponía a disposición sirvió a los inmigrantes europeos -que lo consumieron con tanta fruición como los nativos- como "una forma inmediata y visible de asimilación". Por último, para los grupos dirigentes tradicionales pudo significar "el modo de afirmación de su propia legitimidad y el modo de rechazo de la presencia inquietante del extranjero". Fruto de un momento de grandes cambios, el fenómeno del criollismo popular, según la visión de Prieto, entró en una rápida y "definitiva extinción" a comienzos de la década de 1920, cuando la sociedad se encontró ya más integrada y adaptada a la vida urbana. Le sobrevivió apenas la apropiación de la figura del gaucho por parte de las élites intelectuales que, concluyendo con la famosa intervención de Leopoldo Lugones de 1913, "canonizaron" al Martín Fierro como gran poema nacional, apartándolo del repertorio de héroes de los folletines de consumo popular, considerados de mal gusto y de pobre factura literaria (Prieto 18-22, 132-133, 184 y 187).

En este trabajo quisiera argumentar que el criollismo popular no se extinguió luego de 1920, sino que siguió teniendo una presencia importante al menos hasta comienzos de la década de 1950, momento en el que sería más adecuado situar su ocaso. Para probar esa tesis haremos un recorrido por las historias, escritores y editoriales que dieron vida al fenómeno, especialmente luego de los años veinte. La cronología que propondremos evidentemente echa dudas sobre el peso decisivo que habría tenido la "modernización" en la extinción del criollismo popular, por lo que concluiremos con algunas reflexiones sobre sus posibles motivos, a modo de hipótesis de trabajo. 


\section{Géneros, personajes y formatos}

La literatura del criollismo popular se nutrió de composiciones de género diverso. Limitándonos exclusivamente a los soportes escritos, el corpus central sin duda lo ocuparon las historias trágicas o melodramáticas de gauchos matreros reales o ficticios, de extensión media o larga, compuestas como poemas narrativos o en prosa. Junto con ellas también proliferaron otros géneros y subgéneros. Entre los más frecuentados se cuentan las colecciones de poemas de tono elegíaco y melancólico, que exaltaban la vida rural y las costumbres sencillas del gaucho y se lamentaban por su inminente desaparición (igualmente hubo poemas satíricos, pero fueron la minoría). Los cancioneros también tuvieron una presencia bastante visible, contándose tanto los de cantantes de renombre como las colecciones de composiciones populares anónimas (especialmente vidalitas y milongas). Los payadores publicaron regularmente sus obras y también algunas transcripciones de sus improvisaciones a contrapunto. Con menor frecuencia aparecieron también refraneros y narraciones humorísticas breves (cabe destacar aquí las historias de "cocoliches", italianos acriollados, escritas imitando el habla híbrida de los inmigrantes).

Centrándonos ahora en las historias de gauchos matreros, la gama de personajes que el criollismo aportó fue muy numerosa. Sin embargo, los argumentos solían ser muy parecidos. El modelo fue el de las dos composiciones más populares, que también fueron de las más tempranas: el Martín Fierro de José Hernández y el fuan Moreira de Eduardo Gutiérrez. El argumento habitual, repetido por la mayoría de las obras, giraba en torno de un gaucho que, por la injusta intervención de algún personaje de otro grupo social -un funcionario del Estado, un comerciante, un estanciero- se veía empujado a la mala vida. Habitualmente el gaucho se convertía en matrero luego de "desgraciarse" cometiendo un asesinato, tras lo cual se transformaba en fugitivo y debía luchar por su vida contra quienes trataban de apresarlo. Los finales eran variables: en algunos casos el gaucho terminaba muriendo a manos de la policía o los militares, en otros caía preso y se redimía, o se perdía en la pampa sin que nadie supiera nada de su suerte. En algunas narraciones se incluían historias de amor malogrado, pero no siempre estaban presentes. En este esquema general pueden incluirse a los personajes más emblemáticos, como Agapito Carranza, El gaucho Cañuelas, Los Hermanos Barrientos, Hormiga Negra, Juan Cuello, El Tigre de Quequén, Pastor Luna y muchos otros. Para contrarrestar la figura del criollo rebelde y matrero, algunos escritores pertenecientes a la élite propusieron contrafiguras de criollos mansos, trabajadores o sabios, como el 
Calandria (1896) de Martiniano Leguizamón o Don Segundo Sombra (1926) de Ricardo Güiraldes, pero fueron una pequeña minoría.

Junto a estos arquetipos podemos situar otras narrativas biográficas de personajes históricos que en principio no parecerían reductibles a la figura del matrero, pero que sin embargo circulaban en los mismos formatos y en las mismas colecciones gauchescas que publicaban los editores especializados en el género. Se trata, por caso, de las figuras del Chacho Peñaloza y Aparicio Saravia, dos caudillos populares (riojano el primero, uruguayo el segundo) muertos en situación de luchar contra sus enemigos políticos. Los propios autores de estas historias solían compararlas explícitamente con las de Juan Moreira y otros gauchos levantiscos y las ilustraciones de tapa habitualmente los representaban del mismo modo.

Aunque la mayoría de los personajes clásicos fueron compuestos tempranamente (varios de ellos por Eduardo Gutiérrez), los escritores del género siguieron produciendo nuevas figuras en un número apreciable hasta la década de 1940. Además de los nuevos personajes, abundaron las nuevas versiones de las historias clásicas, que también siguieron componiéndose hasta esos años y que convivían con las reediciones de los originales. Por ejemplo, Martín Fierro, inicialmente publicado en versos que imitaban el habla gauchesca, fue reversionado varias veces, tanto en versos de menor extensión (gauchescos y en castellano normal) como en prosa. Inversamente, varias de las historias que Gutiérrez narró en prosa, especialmente fuan Moreira, fueron reescritas en versos, tanto gauchescos como normales. Incluso un personaje previo como el Santos Vega de Ascasubi inspiró varias nuevas versificaciones. Todo ello debería matizar la diferenciación tajante, habitual en la bibliografía especializada, entre el género de la "poesía gauchesca" (que terminaría con José Hernández) y el del "criollismo" (que comenzaría con Gutiérrez): visto desde el punto de vista de la producción y circulación de los textos de lectura popular, la diferencia específica se vuelve menos nítida.

Además de las reediciones y de las nuevas versiones, hasta mediados del siglo XX aparecieron un número considerable de personajes que llamaremos "derivados", que continuaban o retomaban las historias clásicas (a veces de manera muy libre o solo alegórica). Hubo, por ejemplo, narraciones de la muerte de Martín Fierro, varias historias protagonizadas por sus hijos, al menos tres por sus nietos e incluso una por su esposa. De Juan Moreira hubo reencarnaciones en personajes urbanos, una "Juana Moreira" y al menos un nieto. Juan Cuello y Don Segundo Sombra también dieron lugar a derivados. 
En cuanto a los formatos impresos, algunas de las historias de gauchos aparecieron primero como folletines por entregas, pero la mayoría fueron publicadas de entrada en texto completo. Aunque las historias de quien se considera el iniciador del género, Eduardo Gutiérrez, solían ser bastante extensas (habitualmente de más de 200 o incluso 300 páginas In- $8^{\circ}$ ), los impresos habituales eran mucho más concisos, con una fuerte presencia de folletos de pocas páginas. A partir de la década de 1910 y hasta mediados del siglo, el formato elegido por los editores fue bastante más homogéneo. La gran mayoría de las ediciones fueron cuadernillos de 96 páginas o menos In-12² de papel barato y pliegos intonsos, con tapa coloreada (habitualmente con ilustraciones de gauchos en situación de pelea; para abreviar, en adelante llamaremos "cuadernillo" a este formato).

\section{Los editores}

Entre las primeras casas editoras que dieron vida al fenómeno que nos ocupa, las hubo de diverso tipo. Luego de las primeras ediciones que realizó el mismo diario La Patria Argentina (donde habían salido los folletines), las extraordinarias ventas que obtuvieron las novelas de Eduardo Gutiérrez quedaron en buena medida en manos de N. Tommasi y Maucci, dos editoriales con presencia en el ramo dentro y fuera de la Argentina. El italiano Natalio Tommasi regenteaba un sello que tenía sucursal en Buenos Aires, pero cuya sede era Milán (donde imprimía mucho de lo que vendía en el Río de la Plata). Entre 1884 y 1914 publicó innumerables títulos como parte de su colección "Biblioteca Gauchesca" y también de otros géneros. Por su parte los Maucci, también italianos, fueron una verdadera dinastía de editores unidos por vínculos familiares. Poseían talleres de impresión propios, pero también mandaban a imprimir en Italia y Francia. Establecidos en Buenos Aires en 1892, dominaron el mercado de los libros baratos de temática gauchesca hasta aproximadamente 1910 (Buonocore 90-92).

Fuera de esas dos firmas iniciales, el fenómeno del criollismo popular estuvo animado por editores más pequeños, que en ocasiones vieron la luz para aprovechar las posibilidades comerciales del nuevo género. En el cambio de siglo los principales fueron cuatro. Uno era Juan Antonio Llambías, un modesto librero nacido en Buenos Aires, simpatizante de la UCR, en cuya librería se celebraban payadas y tertulias. Editó obras del criollismo popular entre comienzos de la década de 1890 y los primeros años del nuevo siglo. En el mismo arco temporal, otro modesto librero de Buenos Aires, José Bosch, nacido en Barcelona e hijo de un ebanista, editó materiales de ese tipo. Mucho más prolíficos fueron los hermanos Vicente y Salvador Matera, nacidos en Italia, responsables de una "Biblioteca Criolla" en la que aparecieron más de un 
centenar de títulos entre 1900 y 1910 (Vicente editó algunos solo o en coedición con Longo y Argento todavía en 1920). ${ }^{1}$ Otro prolífico editor fue el asturiano Andrés Pérez, dueño de una librería en el barrio porteño de Monserrat en la que también se celebraban tertulias payadoriles. Su colección "Biblioteca Gauchesca" fue hogar de varias decenas de títulos entre c. 1898 y 1915, los que vendía a 10 o 20 centavos el ejemplar (Buonocore 80, 81, 212-213, 154-157).

Un rasgo compartido de la mayoría de estos editores es que lo eran con fines principalmente comerciales. Dicho de otro modo, no se trataba de editoriales exclusivamente orientadas al rescate de las tradiciones, como las hubo más tarde, sino a vender impresos populares de cualquier tipo. Los hermanos Matera, por caso, también editaban copiosamente literatura europea, mientras que Andrés Pérez ofrecía obras de teatro nacional, novelas, crónicas policiales, textos sobre espiritismo, magia, ciencias ocultas, etc. Además, en estos años el negocio del criollismo dio oportunidades para editores eventuales y para la publicación de autor. Adolfo Prieto identificó un centenar y medio de impresos que aparecieron fuera de las casas editoriales mencionadas, entre los que se contaron muchos que mandaban a imprimir por cuenta propia payadores o escritores; por ejemplo, Santiago Rolleri, un sombrerero montevideano devenido en autor que se autopublicó al menos 48 títulos (Prieto 72).

El panorama de la edición del criollismo popular luego de 1920 y hasta comienzos de los años cincuenta tuvo rasgos similares. Una de las editoriales más prolíficas de todos los tiempos, la de Alfonso Longo, de hecho, publicó antes y después de aquel año. Fue la única relevante en el género que se situó fuera de Buenos Aires, en este caso en Rosario. Sus actividades se iniciaron en c. 1899 con el sello "Librería Americana de José Belluccia", desde la modesta librería que había establecido el siciliano de ese nombre, pronto transferida a su pariente Alfonso Longo, también nacido en Sicilia y de orígenes sociales muy modestos. Hasta 1921 la pequeña editorial, situada en una zona populosa del centro de la ciudad, publicó copiosamente bajo el sello "Longo y Argento" y, luego de la ruptura de la sociedad con el segundo (que también era italiano), con el de "Alfonso Longo". Es difícil saber hasta qué año editaron sus cuadernillos gauchescos; el último que lo consigna de manera explícita es de 1924, pero varias reimpresiones sin fecha sugieren que pueden haber sido posteriores a $1930 .^{2}$ En todo caso

1 Un Francisco Matera publicaba también una "Biblioteca Gauchesca" a finales de la primera década del siglo; seguramente era de la misma familia, aunque no he podido corroborarlo.

2 Las últimas halladas refieren en la publicidad de contratapa a la existencia de traducciones del Martín Fierro a "otros idiomas". Para que el plural no fuera una exageración la publicidad 
sabemos que a más tardar a mediados de los años treinta ya habían abandonado el negocio de la edición. En total Longo publicó más de un centenar de títulos criollistas (además de otros humorísticos, policiales, políticos, románticos, etc.), que ofrecía a un precio que fue de los 10 a los 50 centavos de acuerdo a la época.

Desde fines de los años veinte el epicentro del negocio regresó a Buenos Aires. Desde c. 1928 hasta 1948 la edición de los cuadernillos gauchescos estuvo en lo fundamental en manos de M. Alfredo Angulo y sus "Colecciones Gauchas" (o "Colección Gaucha"), publicadas con su propio nombre y también con los sellos "Publicidad Ateneo" o "Biblioteca Nueva". El formato era muy similar a los de Alfonso Longo, de quien Angulo era amigo (según un informante entrevistado para este trabajo, también era de origen italiano). Hacia 1947 su editorial, situada en el populoso barrio de Constitución, tenía en catálogo 80 títulos gauchescos, 18 de los cuales habían aparecido luego de 1940. Los ofrecía a precios muy populares, 20 centavos al comienzo y \$2 al final. Angulo publicaba también obras populares de otros géneros, incluyendo literatura europea y divulgación científica, y era propietario de la revista El Canta Claro, una de las más vendidas de las dedicadas a la música popular.

Entre 1942 y c. 1959 se sumó la editorial Buchieri, también del barrio de Constitución, con una "Colección Campera" y una "Colección Martín Fierro", desde las que editó al menos 42 títulos gauchescos. Era propiedad de Vicente Buccheri (la diferente grafía no es error) y estaba comercialmente vinculada a la de Angulo -los cuadernillos que publicaban ambos son casi indistinguibles-, del que era además íntimo amigo. Vicente había llegado de niño a la Argentina desde su Sicilia natal y era de condición social muy modesta; trabajando de canillita aprendió a leer por sus medios, ya que nunca fue a la escuela. Hacia 1916, todavía adolescente, comenzó a probar suerte junto a su hermano Blas en el negocio editorial y pronto se transformaron en exitosos editores de la famosa revista El Alma que canta, dedicada a la música popular, a la que le siguieron otras del mismo rubro hasta la década de 1970. Además del género criollista, Buccheri editó también abundantemente en el rubro musical, especialmente folklore, y también obras románticas, de medicina, etc., siempre apuntando al lector popular. ${ }^{3}$ Entre 1943 y 1947 también imprimió al menos 22 títulos gauchescos en formato cuadernillo (algunos de su autoría) Andrés Pérez Cuberes, hijo del editor asturiano Andrés Pérez, de quien hablamos hace un momento, quien continuaba regenteando la librería que había fundado de su padre. ${ }^{4}$

debió ser posterior a 1930.

3 Entrevista a Vicente Buccheri (h.), Buenos Aires, 2 de febrero de 2015.

4 Véase Caras y Caretas, . $^{\circ}$ 1945, 11 de enero de 1936, 70. 
Aunque efímeramente, el último editor comercial relevante de los cuadernillos que nos ocupan fue Caymi, sello que publicó al menos seis títulos entre 1957 y 1959, algunos en coedición con Buchieri, de la que además oficiaba como distribuidor. Caymi, cuyo local quedaba justo en frente del de Angulo (editorial que fue adquirida por Caymi poco antes de la muerte de su fundador), era propiedad de Oscar Cabaleiro, posiblemente hijo de gallegos, hombre dedicado a la distribución de diarios y revistas y a la edición de libros baratos. Publicó varios cientos de títulos económicos de diversas temáticas, especialmente ciencias ocultas, consejos médicos, sexualidad, artes marciales y manuales de mecánica del automotor, entre c. 1945 y la década de 199o. Sin embargo, a partir de los años sesenta solo frecuentó el género criollista muy esporádicamente.

El carácter popular de las editoriales que se ocuparon del negocio de los cuadernillos en el siglo XX se hace evidente en varios indicios. Algunos ya los hemos mencionado: el origen modesto de la mayoría de ellos, las zonas populosas en las que tenían sus establecimientos, la baja calidad de sus impresos y sus módicos precios. Pero además compartían el aprovechamiento de canales informales de distribución que no los hacía depender del público que frecuentaba librerías. Andrés Pérez, por ejemplo, ofrecía sus impresos "por mayor y menor" y tenía lo que él mismo describía como un ejército de vendedores de diarios que los llevaban a toda la ciudad, ${ }^{5}$ además de representantes en ciudades del interior del país (Parodi-Lisi y Morales Saravia 273). Alfonso Longo también vendía al por mayor y tenía vendedores que los ofrecían diariamente en los trenes que unían Rosario y Buenos Aires. Además, había desarrollado un interesante sistema de distribución por correo, que acercaba sus impresos a los pueblos más remotos. Él mismo enviaba gacetillas con el catálogo de sus publicaciones a las personalidades representativas de cada localidad -el presidente de la comisión de fomento, el juez de paz, el comisario-, incluyendo instrucciones para abrir una cuenta corriente y pagar los envíos por giro postal contra reembolso. ${ }^{6}$ Buchieri también tenía sus propios "agentes" y viajaba personalmente a Rosario, donde tenía una buena clientela. Además, distribuía sus materiales la firma Caymi, aprovechando que era proveedora de puestos de diarios. Según un informante, Buchieri vendía especialmente bien en el interior del país. ${ }^{7}$ Los impresos de todas estas editoriales parecen haber llegado hasta los sitios más distantes, como sugiere su presencia en bibliotecas populares de varias provincias.

\footnotetext{
Véase Caras y Caretas, n. ${ }^{\circ}$ 859, 20 de marzo de 1915, 43 y n. ${ }^{\circ}$ 394, 21 de abril de 1906, 55-56.

Entrevista a Amalia Longo (hija de Alfonso), Rosario, 29 de diciembre de 2014.

Entrevista a Vicente Buccheri (h.), Buenos Aires, 2 de febrero de 2015.
} 


\section{Los autores}

En el corpus criollista con el que trabajó, que llega hasta comienzos de la década de 1920, Adolfo Prieto identificó 60 autores, la mayoría de los cuales publicaban muy esporádicamente; unos quince aportaban títulos con mayor regularidad. La cantidad que publicaron algunos de ellos, como Manuel Cientofante (87), Félix Hidalgo (56), Eladio Jasme Ignesón (53), Santiago Rolleri (47) o Silverio Manco (30) y las grandes tiradas que alcanzaron algunos de sus títulos, sugieren que pudieron vivir de la venta de sus textos (una condición profesional que sabemos que Eduardo Gutiérrez en su momento alcanzó) (Prieto 67). Otro indicio en el mismo sentido es que, tal como Gutiérrez, no escribían solo textos de temática gauchesca sino que aportaban también a otros géneros de consumo popular.

Desde el punto de vista de su condición social, tanto Gutiérrez como José Hernández formaban parte de las élites intelectuales y políticas de su época. Pero la gran mayoría de los restantes no pertenecían a ese medio social. Algunos, de hecho, tenían orígenes bastante humildes, como Félix Hidalgo, que ni siquiera había ido a la escuela, o el payador José Betinoti, que antes había sido obrero hojalatero (Contrapunto 2-6; Sánchez Sívori 39). El origen étnico era igualmente variado. Los había criollos (como Gutiérrez, Hernández o el payador Pablo J. Vásquez), pero también inmigrantes italianos (como Silverio Manco y Ambrosio Río) o españoles (como José Alonso y Trelles). Además, dos de los quince autores más prolíficos del corpus de Prieto eran afroargentinos (los payadores Gabino Ezeiza e Higinio Cazón, a los que habría que agregar a Luis García, que también se dedicaba a la payada y publicó sus composiciones).

Desde el punto de vista de los posicionamientos políticos, predominaron claramente las posturas contrarias a la élite conservadora que gobernó el país antes de 1916. Varios autores del criollismo popular apoyaron explícitamente a Leandro Alem, fundador de la Unión Cívica Radical que promovió tres rebeliones armadas hasta que finalmente ganó las primeras elecciones limpias aquel año (Cazón 18; Cientofante, Mi guitarra 19; Vásquez). Otros también se identificaron con la UCR, como Ramón Aguirre, José Betinoti, Félix Hidalgo y Ambrosio Río (Aguirre; Betinoti 28-30; Contrapunto 2-6; Río); Gabino Ezeiza fue un destacado militante de ese partido, al que dedicó varias composiciones (Ezeiza). Algunas de las publicaciones criollistas incluían además como anexos himnos socialistas o llamados a combatir a la burguesía (Cientofante, Martín Fierro 31).

Luego de 1920 la literatura del criollismo popular continuó de la mano de autores de un perfil muy similar al recién reseñado. De hecho, la figura de Silverio Manco -acaso el más prolífico de todos los autores del género- desafía la periodización que propuso Prieto. Había llegado de niño desde su Italia natal (nació 
en Ceniza en 1888) y permaneció activo hasta algunos años antes de su muerte en 1964. De joven abandonó su oficio inicial de peluquero para dedicarse al periodismo -trabajó en el diario Crítica y publicó en muchos otros medios- y fue un prolífico escritor del género que nos compete y de otros, y también de canciones, de guiones de radioteatros y de obras teatrales. En 1907 dirigió la revista porteña La Pampa Argentina y en la década siguiente otras de temática igualmente gauchesca como El Fogón Argentino y Pampa Florida (ambas de Lomas de Zamora) y otros títulos en las ciudades de Azul y Tandil. Más tarde fue Jefe de Redacción de El Alma que Canta, la revista de Buccheri ya mencionada. ${ }^{8}$ Manco tuvo simpatías inicialmente socialistas o anarquistas y luego se volcó al radicalismo (colaboró en periódicos de orientación yrigoyenista), sin dejar de predicar ideas obreristas (Manco Almas que luchan; Milongas para cantar 22; Décimas patrióticas; Musa salvaje passim). Comenzó a publicar versos criollistas e historias de gauchos matreros no bien entrado el siglo XX, editó en los años veinte numerosos títulos con la editorial rosarina de Alfonso Longo y siguió en las décadas posteriores. Solamente en la de 1940 produjo para la editorial Buchieri trece obras gauchescas nuevas (incluyendo reescrituras de los clásicos de Gutiérrez en verso), además de reeditar hasta los años cincuenta algunas de las que había escrito en periodos previos. Entrevistado hacia fines de la década de 1910 dijo que vivía de sus versos (aunque pobremente, según declaró él mismo y confirmó el entrevistador). ${ }^{9}$

Otro de los más prolíficos en el periodo tardío fue Bartolomé R. Aprile. Había nacido en 1894 en el populoso barrio porteño de Barracas, hijo de inmigrantes genoveses. De pequeño trabajó como peón carrero junto a su padre, por lo que se familiarizó con todo lo referente al universo ecuestre de los gauchos. A comienzos de los años treinta participó en la fundación del centro criollo "Leales y Pampeanos" de Avellaneda, por lo que tuvo trato frecuente con los principales poetas y cantores criollos de esos años. Además de sus obras de temática crio-

8 Los datos biográficos fueron tomados de una entrevista del autor a Carlos Manco, nieto de Silverio, realizada el 5 de diciembre de 2014 y complementada con los datos de los sitios: http:// historiando.escribirte.com.ar/13946/silverio-manco-un-escritor-poco-conocido.htm; http://www. lomasysugente.com.ar/2008/octubre2/sumario_biografias.html (acceso 23 de febrero de 2015). En algunos sitios se consigna que Silverio era nacido en Argentina, pero se trata de un error.

9 "La miseria en la literatura: Silverio Manco", Fray Mocho, fecha desconocida, repr. en http:// coleccionesteatrales.blogspot.com.ar/2010/01/silverio-manco-dramaturgo-actor-payador. html (acceso 22 de mayo de 2017). Publicó con su nombre y/o con varios pseudónimos: Flores, Boyero, Alma Nativa, Gaucho Viejo, Paco González, Cacique Viejo, Floreal Medina, Claudio Ataliva, Mirlo Blanco, Julián Ariel de la Cruz, Chingolo, Alma Maleva, Candelario Espumiya, Fierro Chifle, Atahualpa, Cachirulo. 
llista, publicó otras referidas al ambiente urbano y el lunfardo porteño y actuó recitando poemas en la radio. Falleció aún joven en 1941, sin que se le conociera actuación o afinidad política. La intensa labor de escritura en su corta vida sugiere que puede haber vivido de ella. Ya en la década de 1910 publicaba textos en revistas como La Pampa Argentina y más tarde en $\mathcal{N a t i v a ~ y ~ e n ~ o t r a s ~ ( i n c l u y e n d o ~}$ El Alma que canta y El Canta Claro, ya mencionadas). ${ }^{10}$ En total, sin contar los de otros géneros, dejó al menos 38 títulos, entre los que se destacan las narraciones de vidas de matreros de factura propia, otras reescrituras en verso a partir de las historias de Gutiérrez y obras centradas en personajes derivados de los clásicos. Su periodo más prolífico fueron los años treinta, cuando editó sus historias como parte de las "Colecciones Gauchas" de Alfredo Angulo. La cantidad que publicó con ellos sugiere que pudo haber vivido de su trabajo de escritor.

Muchos otros escritores nutrieron el género criollista en las décadas del veinte, treinta y cuarenta. Entre los más destacables por su contribución pueden mencionarse a Policarpo Albarracín (alias Hilarión Abaca), Amando Villador, Andrés Pérez Cuberes y Apolinario Sierra. En los años treinta y cuarenta también continuaban publicando sus obras en editoriales comerciales algunos cantores que continuaron con la tradición de los payadores. Entre ellos se destacaron tres. El rosarino Francisco N. Bianco (1894-1960, alias Pancho Cueva), discípulo de Gabino Ezeiza, hijo de un músico académico, vio las suyas impresas entre las décadas de 1910 y fines de la de 1930 en varias editoriales, incluyendo las de Alfonso Longo y Alfredo Angulo (Sánchez Sívori 44-46). Es el único payador del que hemos encontrado simpatías conservadoras (Bianco 25-26). Por el contrario, Evaristo Barrios (1889-1959), nacido en un pueblo bonaerense cercano a La Plata, criollo y de condición social humilde, fue socialista (Sánchez Sívori 37-39; Barrios). Dedicado a la payada ya desde la década de 1910, dejó una veintena de obras impresas, la mayoría publicadas en los años cuarenta con la editorial Buchieri. Finalmente, el más famoso de los tres, Martín Castro (1882-1971), nacido en el pueblo bonaerense de Merlo, criollo y de origen social modestísimo, militante anarquista (y luego simpatizante del peronismo), dejó 16 compilaciones con sus composiciones y un notable y extenso poema narrativo centrado en la vida de un gaucho matrero, titulado Los gringos del país (c. 1937). La mayoría de las de temática gauchesca aparecieron entre 1928 y 1952 en la casa editora de Angulo (Adamovsky "Criollismo, política"). A ellos podría agregarse a Antonio Caggiano (1881-1955), que ya era un payador conocido a comienzos de siglo y también siguió publicando sus composiciones hasta los años cincuenta.

10 Los datos biográficos están tomados de Aprile (7-43) y Risso. 
Cabe destacar que también en estos años hubo otros autores de temática gauchesca que, por su perfil y tipo de producción, no corresponde considerar parte del fenómeno del criollismo popular. El Don Segundo Sombra de Ricardo Güiraldes apareció en 1926 y pronto se convirtió en uno de los personajes gauchescos más famosos de todos los tiempos, con numerosas reediciones hasta la actualidad. Pero, aunque Luis Acosta la reversionó y Bartolomé Aprile compuso a partir de ella un personaje derivado (ambos para el sello de Angulo), la obra de Güiraldes, protagonizada por un gaucho manso y ejemplar, en verdad circuló por los carriles de la literatura "culta". Publicada inicialmente por la editorial Proa (que editaba entre otros a Borges), fue canonizada como obra de valor literario desde un comienzo. Su autor, por lo demás, provenía de los sectores sociales más encumbrados. Otro de perfil similar, también de familia patricia, fue Julio Díaz Usandivaras (18881962), fundador de la revista Nativa y prolífico autor de cuentos y poemas gauchescos que vieron la luz en la década de 1910 y en las dos siguientes, cuya circulación fue también diferente a la del criollismo popular.

\section{¿Hasta cuándo?}

Hemos establecido hasta aquí que el criollismo popular siguió contando con autores y editores que lo frecuentaran al menos hasta comienzos de los años cincuenta. ¿Es posible, sin embargo, que su producción y circulación disminuyera dramáticamente luego de 1920, como afirmó Prieto? Ya que los datos disponibles no permiten ejercicios con validez estadística, avanzaremos con algunos indicios alternativos.

Los impresos del criollismo popular en el cambio de siglo podían tener suerte muy variable entre el público lector. El Martín Fierro y el fuan Moreira originales conocieron múltiples reediciones y tiradas sorprendentemente grandes para su época (aunque igualmente notable fue la cantidad de ejemplares que vendió la edición popular del primero que Eudeba lanzó en 1962, que superó los 220000 en sus primeros diez años, con siete ediciones). Pero para el resto de los textos tempranos el panorama fue más variado. Como mostró Prieto, en el cambio de siglo no era infrecuente que un folleto vendiera múltiples ediciones en pocos meses. Un puñado de las más exitosas incluso llegaron a las 15017 reimpresiones. Una tirada particularmente alta y digna de mención a efectos promocionales podía ser de 10 ooo ejemplares o en algún caso el doble (Prieto 68). Para la mayoría de las obras, sin embargo, la recepción del público lector parece haber sido menos brillante. 
La comparación con las ediciones posteriores es muy complicada por falta de datos. Alfonso Longo hizo tres, cuatro y hasta siete ediciones de algunos de sus títulos, pero desconocemos las tiradas. De M. Alfredo Angulo casi nada sabemos; indudablemente reimprimía los suyos, pero nunca dejaba registrado el número de reedición ni el nuevo año. En cuanto a las tiradas, sabemos que una de sus compilaciones de payadas del año 1947 (que ya había conocido una edición anterior) imprimió 10000 ejemplares. Los títulos no gauchescos de Angulo de ese mismo año tuvieron tiradas de la mitad o menos, lo que podría sugerir que las de temática criolla eran más vendedoras. ${ }^{11}$ De Buchieri sabemos que hizo al menos dos ediciones de varias de sus obras, pero tampoco es seguro que siempre consignara el número de reimpresión. En cuanto a tiradas, de dos publicadas en 1948 sabemos que imprimió 10 ooo ejemplares. ${ }^{12}$

El siguiente gráfico intenta presentar toda la información disponible de manera inteligible. Ya que, del universo de los textos de temática gauchesca, no siempre es sencillo distinguir los que corresponde considerar del tipo popular, trabajé en este gráfico únicamente con su núcleo principal: las historias de gauchos matreros (a las que agregué las nuevas versiones y "derivados" de las de gauchos mansos), fueran o no escritas y publicadas por el tipo de autores y editores descritos en este trabajo. De este modo, quedan afuera de este ejercicio los otros tipos de registro, como las colecciones de canciones, payadas, poemas, etc. La idea era poder visualizar con qué intensidad siguieron apareciendo reediciones y nuevas historias según pasaban las décadas. Cada punto negro indica la aparición de una nueva historia o la reaparición de una anterior en otra casa editorial (el conteo se reinicia para cada década, de modo de saber cuántas ediciones estuvieron disponibles en cada decenio). Al mismo tiempo incluí tres grisados para ponderar cantidad de reimpresiones que hubo en cada década de cada edición singular: el más oscuro indica 7 o más reimpresiones de una de las ediciones o en total; el intermedio de 4 a 6 y el más claro de 2 a 3 (si una reimpresión cae en otro decenio, se computa en el siguiente). Para evitar distorsiones que pudieran beneficiar indebidamente mi argumento, retiré dos obras canónicas que siguieron reeditándose continuamente hasta hoy: del Martín Fierro original solo incluí las reediciones hasta la década de 1890 y de Don Segundo Sombra, solo la primera edición. El resultado es el que se aprecia en la siguiente tabla.

1 Véase Boletín Oficial de la República Argentina, 1ra. secc., 28 de junio de 1948.

12 Véase Boletín Oficial de la República Argentina, 1ra. secc., 24 de mayo de 1948. 


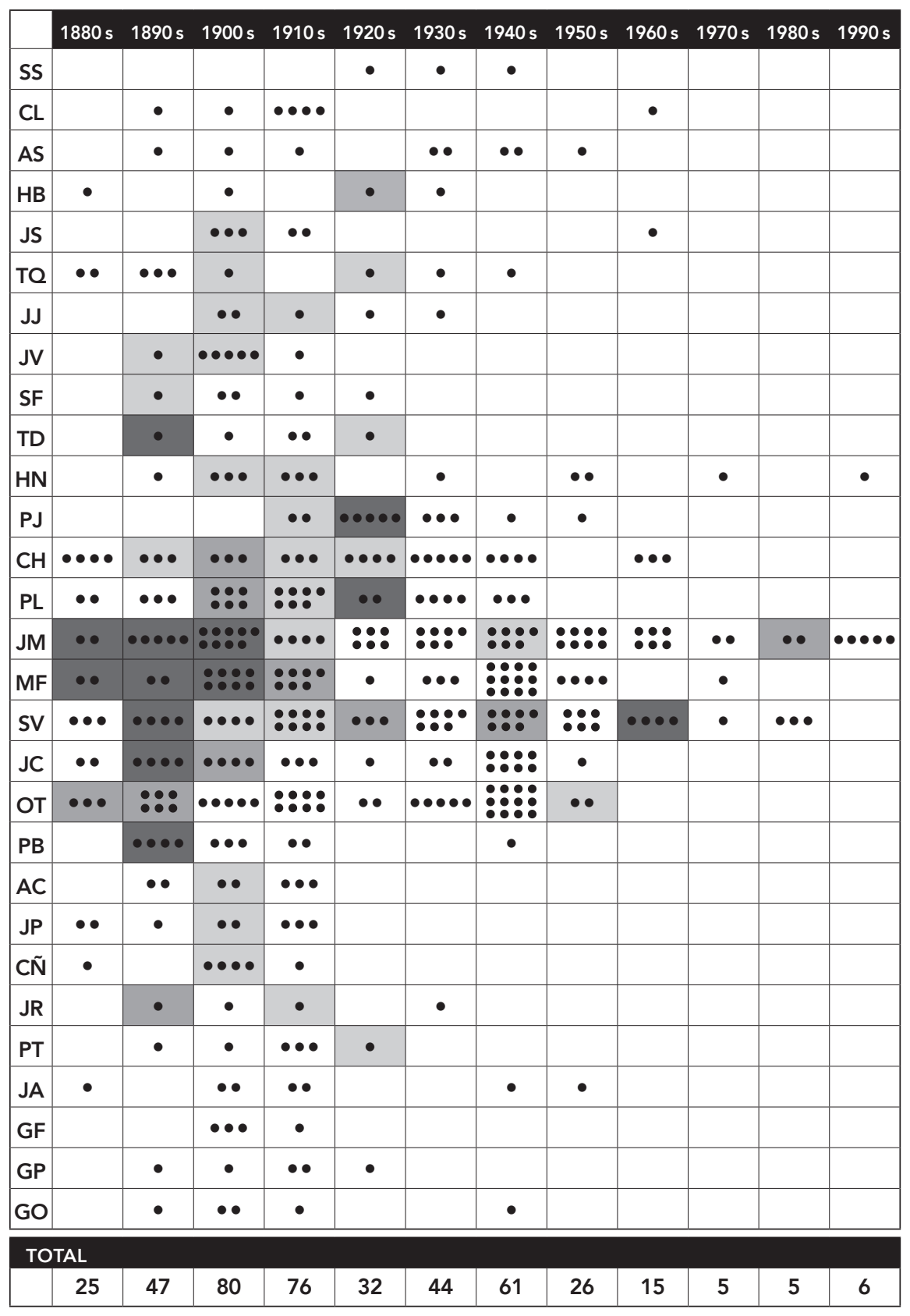

Tabla 1. Ediciones de historias de gauchos según personaje y década ${ }^{13}$

13 Ver listado completo en el Anexo. 
Como puede observarse a simple vista, la intensidad es particularmente fuerte en las décadas de 1890 y 1900 y menor en las siguientes. Pero no se observa una desaparición drástica en los años veinte. Las historias de gauchos matreros siguen apareciendo con intensidad al menos hasta fines de la década de 1940 y comienzos de la siguiente, para decaer con claridad a partir de los años sesenta. No se visualiza un quiebre particular en los años veinte (las columnas de los dos decenios siguientes son tanto o más nutridas). Nótese además que la amplitud vertical del gráfico se reduce visiblemente, pero en los años cuarenta la fila miscelánea "Otros" es la más nutrida de la serie ( si hubiéramos colocado cada título en una fila aparte, la imagen no daría la impresión de una menor diversidad de historias). Debe tenerse en cuenta, además, que seguramente todo el periodo dominado por las ediciones de Angulo está subvalorado por la ausencia total de datos de reedición, mientras que, por el contrario, el periodo anterior a 1920 está sobrerrepresentado porque hasta entonces Roberto Lehmann-Nitsche se dedicó ex profeso a reunir textos criollistas de circulación popular (de no haberse preservado su colección en Berlín, hoy ni siquiera tendríamos noticias de la existencia de buena parte de los impresos del periodo temprano).

En el centro del eje vertical hemos colocado deliberadamente a los personajes más famosos (Juan Moreira y otros de Gutiérrez, Martín Fierro, Santos Vega). Como puede verse, esos son los de mayor longevidad. Pero se verifica un cambio interesante en las ediciones: luego de los años cincuenta prácticamente deja de haber obras derivadas y reversiones, y las pocas reediciones de los textos clásicos dejan de estar en manos de editores populares, para quedar a cargo de editoriales "cultas" - como Eudeba, Hachette o Perfilque ofrecen ediciones establecidas y/o prologadas por especialistas. En otras palabras, la sobrevida del criollismo popular depende de un lector implícito que ya no es tanto el popular sino el especializado.

En fin, este gráfico no tiene ninguna pretensión de solidez estadística: se trata apenas de un ejercicio sinóptico meramente indicativo que, además, tampoco tiene modo de sopesar los datos con la evolución general del mercado editorial, que tuvo un crecimiento explosivo luego de 1935. Con todos estos recaudos, es sin embargo posible concluir que luego de 1920 (o mejor, 1910) hubo sin dudas una menor intensidad en la circulación y producción del criollismo popular, pero que no se trató de una disminución abrupta. No hubo en los años veinte una "definitiva extinción" del fenómeno del criollismo popular, como supuso Prieto. Por el contrario, correspondería resituar el final de la pregnancia de ese género en los albores de los años cincuenta. Su 
persistencia fue tal, que todavía en la segunda presidencia de Perón su aparato propagandístico traficaba mensajes políticos mediante folletos de versos gauchescos con tapa a color, similares a los que se vendían en el mercado, firmados por Zoilo Laguna (Adamovsky "El criollismo").

Si en lugar de limitar la pregunta a los impresos ampliáramos la lente para incluir todos los demás formatos, la perdurabilidad del criollismo popular aparecería con más claridad. Un relevamiento de 1948 encontró que estaban deambulando por entonces unos 200 circos criollos por todo el país, con repertorios en los que fuan Moreira y otros dramas gauchescos seguían siendo un número central (yo mismo alcancé a ver una puesta de niño, en el conurbano bonaerense, a mediados de la década de 1970) (Gorostiaga 152). Lo mismo vale para las compañías de teatro, especialmente fuera de Buenos Aires: por ejemplo en Resistencia y en pueblos del Chaco eran bien habituales en los años cuarenta y cincuenta (Capetinich, Historia del teatro 40-47). El radioteatro también transitó largamente el género en diversas regiones; todavía a mediados de la década de 1980 la compañía sanjuanina que representaba la historia "El gaucho José Dolores, protector de los humildes" alcanzó gran éxito en una emisora local y en giras por los pueblos de la provincia. ${ }^{14} \mathrm{El}$ cine siguió generando éxitos con historias de matreros, incluyendo una nueva versión fuan Moreira en 1948 y otra todavía en 1973, la de Leonardo Favio, que fue un suceso de público (Tranchini; Lusnich). Lo mismo vale para la historieta, que dio versiones de fuan Cuello, Hormiga Negra, Santos Vega y otras en diarios y revistas de los años cuarenta, cincuenta y sesenta (Gociol y Rosemberg 289-298). Los principales cantantes folklóricos de los años sesenta y setenta continuaban transitando repertorios con historias de gauchos y grabando composiciones de los viejos payadores. ${ }^{15} \mathrm{E}$ incluso en el carnaval porteño se presentaron regularmente comparsas gauchescas al menos hasta fines de la década de 1950 (Romero 213 y 223).

En conclusión, lejos de extinguirse, el criollismo popular siguió ocupando un lugar central en la cultura argentina durante toda la primera mitad del siglo XX. Excede los fines de este trabajo avanzar en una explicación alternativa, pero todo sugiere que interpretarlo como un fenómeno alumbrado por las tensiones de la modernización (y que por ello finalizó con ellas) no resulta satisfactorio. Como propuse en otra parte, su perdurabilidad acaso se explique, al menos parcialmente, por el hecho de que desempeñó una

14 Véase Diario de Cuyo (San Juan), 12 de abril de 1984.

15 Por ejemplo, Horacio Guarany canta a Martín Castro (Philips). 
cuarta función, que habría que sumar a las ya identificadas por Prieto. El interés por el mundo criollo y lo gauchesco, y los sentidos disímiles que le adjudicaban el criollismo popular y el de élite, son indicios de la persistencia de luchas profundas por la definición del perfil del pueblo argentino. Dicho en otras palabras, el criollismo popular fue uno de los canales por los que transitó el largo (acaso todavía inconcluso) proceso de etnogénesis en Argentina, es decir, la formación de un ethnos nacional a partir de la heterogeneidad de los componentes demográficos del país y de las tensiones que agregaba entre ellos la superposición de las jerarquías de clase y étnicas y las narrativas contrapuestas por las que intentaron dar cuenta de quiénes eran. Puede que el criollismo popular siguiera siendo atractivo, entre otras razones, porque permitía hacer visible y tematizar la heterogeneidad étnica de la nación, en particular su componente mestizo y sus colores noblancos, invisibilizados por un discurso oficial que la postulaba blanca y de origen europeo. La evocación del mundo gauchesco abría las puertas para la visibilización de la presencia de indígenas y afroargentinos, de cruces y mestizajes varios y de colores de piel que no se asimilaban fácilmente al "blanco". Y también para señalar el lugar socialmente subordinado que les tocaba a los criollos en general, tuvieran o no esas marcas (Adamovsky "La cuarta función", "El criollismo").

\section{Obras citadas}

Adamovsky, Ezequiel. "Criollismo, política y etnicidad en la obra de Martín Castro, cantor anarquista (c. 1920-1950)". Quinto Sol 20.3 (septiembre-diciembre de 2016): 1-26. Impreso.

Adamovsky, Ezequiel. "El criollismo en las luchas por la definición del origen y el color del ethnos argentino, 1945-1955". Estudios Interdisciplinarios de América Latina y el Caribe 26.1 (2015): 31-63. Impreso.

Adamovsky, Ezequiel. "La cuarta función del criollismo y las luchas por la definición del origen y el color del ethnos argentino (desde las primeras novelas gauchescas hasta c. 1940)". Boletín del Instituto de Historia Argentina y Americana "Dr. Emilio Ravignani"

Tercera serie.41 (segundo semestre de 2014): 50-92. Impreso.

Aguirre, Ramón. Cantos radicales. Rosario: Longo y Argento, s.f. Impreso.

Aprile, Bartolomé. Arrabal salvaje. Buenos Aires: Freeland, 1964. Impreso.

Barrios, Evaristo Barrios. La guitarra de Martín Fierro.

Buenos Aires: Buchieri, 1947. Impreso.

Betinoti, José. De mi cosecha. Buenos Aires: Andrés Pérez, s.f. Impreso. 
Bianco, Francisco N. El zorzal criollo. Buenos Aires:

Colecciones Gauchas, 1939. Impreso.

Buonocore, Domingo. Libreros, editores e impresores de Buenos

Aires. Buenos Aires: Bowker, 1974. Impreso.

Capetinich, Mirna. Historia del teatro en el Chaco (1900-1967).

Resistencia: Librería de la Paz, 2012. Impreso.

Cazon, Higinio D. Colección de canciones del payador argentino

Higinio D. Cazón. 1er. libro, 4ta. ed. s.l.: s.f. Impreso.

Cientofante, Manuel. Martín Fierro. Buenos Aires: Andrés Pérez, s.f. Impreso.

Cientofante, Manuel. Mi guitarra. Buenos Aires: Matera, 1909. Impreso.

Contrapunto entre Gabino Ezeiza y Félix Hidalgo. Buenos

Aires: Bibl. Gauchesca, 1901. Impreso.

Ezeiza, Gabino. Glorias radicales. Rosario: Longo y Argento, s.f. Impreso.

Gociol, Judith y Diego Rosemberg. La historieta argentina: una historia. Buenos Aires: De la Flor, 2000. Impreso.

Gorostiaga, Manuel R. "Nuestros intérpretes musicales se acercan, en lo posible, a las fuentes propias". Continente, febrero de 1948. Impreso.

Lusnich, Ana Laura. El drama social-folclórico: el universo rural en el cine argentino. Buenos Aires: Biblos, 2007. Impreso.

Manco, Silverio. Almas que luchan. Rosario: José Belluccia, s.f. Impreso.

Manco, Silverio. Décimas patrióticas. Buenos Aires:

Biblioteca Gauchesca, s.f. Impreso.

Manco, Silverio. Milongas para cantar con guitarra. Buenos Aires: Biblioteca Gauchesca, s.f. Impreso.

Manco, Silverio. Musa salvaje. Córdoba: Buchardo, 1913. Impreso.

Parodi-Lisi y José Morales Saravia. "La pampa argentina: Una revista criollista en el Río de la Plata. Un planteamiento de la cuestión". Revista de crítica literaria latinoamericana 30 (1989): 259-275. Impreso.

Prieto, Adolfo. El discurso criollista en la formación de la Argentina moderna. Buenos Aires: Siglo veintiuno, 2006. Impreso.

Rio, Ambrosio. Poesías agrestes. Buenos Aires: Andrés Pérez, 1912. Impreso.

Risso, Carlos R. "Bartolomé Rodolfo Aprile, un poeta olvidado". http://carlosraulrisso-escritor.blogspot.com.ar/2012/o9/bartolomerodolfo-aprile-un-poeta.html. Web. 23 de diciembre de 2015.

Romero, Coco. La murga porteña. Buenos Aires: CICCUS, 2013. Impreso.

Sánchez Sívori, Amalia. Diccionario de payadores.

Buenos Aires: Plus Ultra, 1979. Impreso. 
Tranchini, Elina. "El cine argentino y la construcción de un imaginario criollista". El cine argentino y su aporte a la identidad nacional. Buenos Aires: FAIGA, 1999. 103-170. Impreso.

Vásquez, Pablo J. La muerte del Dr. Leandro $\mathcal{N}$. Alem. 2 da. ed. Buenos Aires: Llambías, 1896. Impreso.

\section{ANEXO}

Obras utilizadas para la confección del gráfico (ordenadas por personaje)

\section{AGAPITO CARRANZA (AC)}

Abaca, Hilarión. Agapito. Rosario: Longo y Argento, s/f. Impreso.

Alma Nativa. Agapito. Buenos Aires: s.f. Impreso.

Casas, Ángel. El gaucho Agapito. Rosario: Longo y Argento, s. f. Impreso.

Hidalgo, Félix. Agapito, su triste fin y los amores con una canaria.

Buenos Aires: Bibl. Gauchesca, 1899. Impreso.

Hidalgo, Félix. Agapito, su verdadera historia. Buenos

Aires: El Progreso Literario, 1894. Impreso.

Jasme Igneson, Eladio. Agapito, su verdadera historia en verso.

Buenos Aires: Bibl. Gauchesca, 1904. Impreso.

Vida y fusilamiento del desgraciado Agapito. Buenos Aires:

Salvador Matera, 1906. (Otra ed. 1901). Impreso.

\section{APARICIO SARAVIA (AS)}

Aprile, Bartolomé. Aparicio Saravia. Buenos Aires:

Colecciones Gauchas, 1936. Impreso.

Bonelli, Ángel. Aparicio Saravia. Buenos Aires: Colección Gaucha, 1939. Impreso.

Gálvez, Manuel. Vida de Aparicio Saravia: el gaucho de la libertad. Buenos

Aires: Tor, 1957. (Ed. anterior de Imprenta López, 1942). Impreso.

La Revolución oriental: detalles completos de las

principales batallas. S.1., 1905. Impreso.

Manco, Silverio. Homenaje al malogrado general

Aparicio Saravia. S. 1., s. f. Impreso.

Revolución Oriental: entrada de los blancos en Montevideo.

Buenos Aires: Andrés Pérez, 1897. Impreso.

Sierra, Apolinario. Aparicio Saravia. Buenos Aires: Publicidad

Ateneo - Colección Gaucha, s.f. Impreso. 


\section{CALANDRIA (CL)}

Calandria. Buenos Aires: Salvador Matera, 1910. Impreso.

En Catálogo. Calandria. Rosario: Longo y Argento, s.f. Impreso.

Leguizamón, Martiniano. Calandria. Buenos Aires: Ivaldi y Checchi,

1898. (Otra ed. Buenos Aires: Solar - Hachette, 1961). Impreso.

Leguizamón, Martiniano. "Calandria". Bambalinas II.88 (1919). Impreso.

Manco, Silverio. El gaucho Calandria. Buenos Aires: Bibl. Criolla, s.f. Impreso.

Vida y combates del famoso gaucho entrerriano Calandria. Buenos

Aires: Salvador Matera - Bibl. Criolla, 1901. Impreso.

\section{CAÑUELAS (CÑ)}

Aguirre, Ramón. El gaucho de Cañuelas. Rosario: Alfonso Longo, s.f. Impreso.

Cientofante, Manuel. El gaucho de Cañuelas. Buenos

Aires: Salvador Matera, 1900. Impreso.

El gaucho de Cañuelas. La Morocha y otras canciones populares.

Buenos Aires: Andrés Pérez, 1907. Impreso.

Lamadrid, F. A. El gaucho de Cañuelas. Buenos Aires: Pedro Irume, 1887. Impreso.

Lamadrid, F. A. El gaucho de Cañuelas, primera parte. Buenos

Aires: Bibl. Gauchesca, 1904. (Otra ed. de 1901). Impreso.

Lamadrid, F. A. El gaucho de Cañuelas, segunda parte.

Buenos Aires: Bibl. Gauchesca, 1905. Impreso.

\section{CHACHO PEÑALOZA (CH) y secuelas}

Alma Nativa. El Mataco y El Chacho. S.l., s.f. Impreso.

Alma Nativa. El Tigre del Desierto y Los Montoneros. S.l, s.f. Impreso.

Aprile, Bartolomé. El alma de la montonera. Buenos Aires:

Alfredo Angulo - Colecciones gauchas, 1935. Impreso.

Aprile, Bartolomé. El Chacho. Buenos Aires: Publicidad

Ateneo - Colección Gaucha, s.f. Impreso.

Brancatti, F. El Chacho. Buenos Aires: Buchieri, 1949. Impreso.

Chávez, Fermín. Vida del Chacho. Buenos Aires: Ediciones Theoría, 1962. Impreso.

Corvalan Mendilaharsu, Dardo. El Chacho. Buenos Aires: 1914. Impreso.

Gutiérrez, Eduardo. El Chacho. Buenos Aires: N. Tommasi, s.f. (Otras eds.

Buenos Aires: Maucci, 1892 y 1895; Buenos Aires: Hachette, 1960). Impreso.

Gutiérrez, Eduardo. El rastreador. Buenos Aires: Tommasi, s.f. Impreso.

Gutiérrez, Eduardo. La muerte de un héroe. Buenos Aires: Tommasi, s.f. Impreso.

Gutiérrez, Eduardo. Los Montoneros. Buenos Aires: Tommasi, s.f. Impreso. 
Hernández, José. Vida del Chacho. Paraná: El Argentino, 1863. (Otras eds.

Buenos Aires: Ángel Da Ponte, 1875; Buenos Aires: Reconquista, 1939; Mar del Plata: Forja, 1943; Buenos Aires: Antonio Dos Santos, 1947). Impreso.

Jasme Igneson, Eladio. El Chacho en versos gauchescos. Buenos Aires:

Bibl. Gauchesca, 1897. (Otras eds. de 1900 y 1905). Impreso.

Jasme Igneson, Eladio. El rastreador. Buenos Aires: Bibl.

Gauchesca, 1900. Otra ed. de 1902. Impreso.

Jasme Igneson, Eladio. Muerte de un héroe. Buenos Aires: Imprenta de las

Provincias, 1894. (Otra ed. Buenos Aires: Bibl. Gauchesca, 1902). Impreso.

Manco, Silverio. El Chacho. Rosario: Alfonso Longo, 1924. Impreso.

Manco, Silverio. El rastreador. Rosario: Alfonso Longo, s.f.

(Otra ed. Buenos Aires: Bibl. Nueva, 1948). Impreso.

Manco, Silverio. La muerte de un héroe. 2da. ed.

Rosario: Alfonso Longo, s.f. Impreso.

Manco, Silverio. Los Montoneros. Rosario: Alfonso Longo, s.f. Impreso.

Marsili, Ernesto. "La mujer del Chacho". La Escena 655 (1931). Impreso.

\section{DON SEGUNDO SOMBRA (SS)}

Acosta, Luis. Don Segundo Sombra. Buenos Aires: Publicidad

Ateneo - Colección Gaucha, 1947. Impreso.

Güiraldes, Ricardo. Don Segundo Sombra. Buenos Aires: Proa, 1926. Múltiples reediciones. Impreso.Aprile, Bartolomé. El ahijado de Don Segundo Sombra. Buenos Aires: Plus Ultra, 1935.

(Otra ed. Buenos Aires: Alfredo Angulo, s.f.). Impreso.

\section{GAUCHO DE LA FRONTERA (GF)}

Alma Nativa. El gaucho de la frontera; fusticia! Buenos

Aires: Andrés Pérez, s.f. Impreso.

Cientofante, Manuel. El gaucho de la frontera. Buenos Aires:

Francisco Matera - Bibl. Campera, 1909. Impreso.

El gaucho de la frontera. Buenos Aires: Bibl. Criolla - Salvador Matera, s.f. Impreso.

En Catálogo. El gaucho de la frontera. Rosario: Longo

y Argento, s.f. Anterior a 1913. Impreso.

\section{GAUCHO DE SANTA FE (SF)}

Cientofante, Manuel. El gaucho de Santa Fé. Buenos Aires:

Francisco Matera - Bibl. Campera, 1909. Impreso.

El gaucho de Santa Fe. Buenos Aires: Bibl. Criolla - Salvador Matera, s.f. Impreso. 
Irellor, Santiago. El gaucho de Santa Fé. zra. ed. Buenos Aires - Montevideo: S. Rolleri, 1897. Impreso.

Manco, Silverio. El gaucho de Santa Fe. Rosario: Longo y Argento, 1921. (Otra ed. anterior a 1913). Impreso.

\section{GAUCHO PICARDÍA (GP)}

Berón, Sebastián C. El gaucho Picardía. Buenos Aires: José Bosch, s.f. Impreso. Cientofante, Manuel. El gaucho Picardía. Buenos Aires:

Francisco Matera - Bibl. Campera, 1909. Impreso.

El gaucho picardía. Buenos Aires: Bibl. Criolla - Salvador Matera, 1910. Impreso. Manco, Silverio. El gaucho Picardía. Rosario: Longo y

Argento, 1921. (Otra ed. anterior a 1913). Impreso.

\section{HERMANOS BARRIENTOS (HB)}

Amante, Ángel. Los hermanos Barrientos. Rosario: Alfonso

Longo, s.f. (Al menos 4 eds.). Impreso.

Aprile, Bartolomé. Los hermanos Barrientos. Buenos Aires: Angulo, 1935. Impreso.

Gutiérrez, Eduardo. Los hermanos Barrientos.

Buenos Aires: Tommasi, s.f. Impreso.

Jasme Igneson, Eladio. Los hermanos Barrientos. Buenos

Aires: Bibl. Gauchesca, 1905. Impreso.

\section{HORMIGA NEGRA (HN)}

Abaca, Hilarión. Hormiga Negra. 3ra. ed. Rosario:

Alfonso Longo, s.f. (1919). Impreso.

Albarracín, Policarpo. El gaucho Hormiga Negra.

Rosario: Longo y Argento, s.f. Impreso.

Alma Nativa. Zuan sin Patria y Hormiga Negra. S.l, s.f. Impreso.

Aprile, Bartolomé. Hormiga Negra. Buenos Aires: Angulo, 1935. (Otra

ed. Buenos Aires: Caymi - Bibl. Nueva, 1957). Impreso.

Cientofante, Manuel. Hormiga Negra. Buenos Aires: Andrés Pérez, 1905. Impreso.

Fragmentos de la vida de Guillermo Hoyo o sea el gaucho Hormiga Negra.

Buenos Aires: Bibl. Criolla - Salvador Matera, 1900. Impreso.

Gutiérrez, Eduardo. Hormiga Negra. Buenos Aires: Tommasi,

s.f. (Otras eds. Buenos Aires: El boyero, 1950; Buenos Aires:

Conjunta, 1977; Buenos Aires: Perfil Libros, 1999). Impreso. 
Jasme Igneson, Eladio. Hormiga Negra. Buenos Aires: Bibl.

Gauchesca, 1897. (Otras eds. de 1900, 1902, 1904). Impreso.

\section{JUAN ACERO (JA)}

Alma Nativa. Fuan Acero. S.l, s.f. Impreso.

Barrios, Evaristo. Fuan Acero. Buenos Aires: Publicidad Ateneo - Colección

Gaucha, 1945. (Otra ed. Buenos Aires: Caymi, 1959. Impreso.

Culebra, Anastasio. El gaucho fuan Acero, rival de Martín Fierro.

Montevideo: Juan B. Vaillant, 1885. (Otra ed. 1901). Impreso.

En catálogo. Fuan Acero. Rosario: Longo y Argento, s.f. Impreso.

Vida del valiente gaucho oriental fuan Acero. Buenos

Aires: Bibl. Criolla - Salvador Matera, 1901.

\section{JUAN CUELLO (JC) y secuelas}

Aguirre, Ramón. Fuan Cuello. Rosario: Longo y Argento, s.f. Impreso.

Aprile, Bartolomé. Fuan Cuello. Buenos Aires: Bibl. Nueva, 1944. Impreso.

Aprile, Bartolomé. Fuan de la Cruz Cuello. Buenos Aires: A. Angulo, 1935. Impreso.

Arditi Rocha, René y Enrique Ramírez. Los gauchos descamisados:

fuan Cuello. Buenos Aires: Tú y Yo, 1948. Impreso.

Berón, Sebastián C. La muerte de fuan Cuello. 12ma. ed.

Buenos Aires: Llambías, 1897. Impreso.

Blomberg, Héctor Pedro. Fuan Cuell: el romántico rebelde. Buenos

Aires: Talleres Gráficos "Cruz del Sur", 1941. Impreso.

Caraballo, Gustavo. "Juan Cuello". Bambalinas 155 (1921). Impreso.

Caraballo, Gustavo. "Juan Cuello: leyenda argentina en dos actos

y siete cuadros". Argentores VII.204 (1941). Impreso.

Compendio de la vida de fuan Cuello y relato fiel de su triste muerte.

Buenos Aires: Salvador Matera - Bibl. Criolla, 1900. Impreso.

Cosentino, Oreste A. "Juan de la Cruz Cuello". Candilejas 2.7 (1944). Impreso.

En catálogo. Historia en verso de fuan de la Cruz Cuello. Rosario:

Longo y Argento, s.f. (previo a 1913). Impreso.

Fontanella, Agustín. Fuan Cuello. Buenos Aires: 1909. Impreso.

Gutiérrez, Eduardo. Fuan Cuello. Buenos Aires: Imprenta de La Patria

Argentina, 1880. (Otras eds. Buenos Aires: Tommasi, s.f.; Buenos

Aires: Domingo Ferrari, s.f.; Buenos Aires: Tor, 1951). Impreso.

Hidalgo, Félix. Fuan Cuello. Buenos Aires: Imprenta de las Provincias, 1893. (Otras tres eds. de Bibl. Gauchesca 1901, 1902, 1904). Impreso.

Manco, Silverio. Fuan Cuello. Buenos Aires: Buchieri, 1943. Impreso. 
Peña, Raúl M. de la. Fuan Cuello. 2da. ed. Buenos Aires: Buchieri, 1944. Impreso. Pérez Cuberes, Andrés. Fuan Cuello. Buenos Aires: Pérez Cuberes, 1947. Impreso.

Roberto, Germán. Fuan Cuello. Rosario: Longo y Argento, s.f. Impreso.

Sallot, Juan Eugenio. Fuan Cuello. Buenos Aires: Vicente

Matera - Bibl. Criolla, s.f. Impreso.

Salto, Luis del. Historia en verso de fuan de la Cruz Cuello. Buenos

Aires: 1900. (Otras eds. de 1904 y 1905). Impreso.

Sierra, A. Fuan Cuello. Buenos Aires: Colección Gaucha, s.f. Impreso.

\section{JUAN EL RASTREADOR (JR)}

Berón, Sebastián C. Fuan el rastreador. 4 ta. ed. Buenos

Aires: Bibl. gauchesca, 1897. Impreso.

Manco, Silverio. Fuan el Rastreador. Buenos Aires: Bibli Criolla, s.f. (c. 1900). (Otras eds. 2da. ed. Rosario: Longo y Argento, s.f.; Buenos Aires: Colecciones Gauchas, s.f.). Impreso.

\section{JUAN MOREIRA (JM)}

Aguirre, Ramón. Fuan Moreira. Rosario: Longo y Argento, s.f. Impreso.

Aguirre, Ramón. La muerte de fuan Moreira. Rosario:

Longo y Argento, s.f. Impreso.

Amante, Ángel. Fuan Moreira. Rosario: Longo y Argento,s.f. (c. 1920). Impreso.

Aprile, Bartolomé. La muerte de fuan Moreira. Buenos

Aires: A. Angulo, 1937. Impreso.

Berón, Sebastián C. La muerte de fuan Moreira. 17ma. ed. Buenos

Aires: Llambías, 1899. (Hay ed. de 1891). Impreso.

Bosque, Horacio del. Fuan Moreira. Buenos Aires: Andrés

Pérez, s.f. Otras dos ediciones. Impreso.

Capdevila, Rafael Darío. Gauchos célebres: Fosé Luis Molina

[y] Fuan Moreira. Tapalqué: Patria, 1972. Impreso.

Cientofante, Manuel. Fuan Moreira. Buenos Aires: Salvador Matera, 1905.

(Es el mismo texto que el anterior; hay otra ed. de 1908). Impreso.

Cientofante, Manuel. Vida y muerte de fuan Moreira.

Buenos Aires: Salvador Matera, 1900. Impreso.

Expósito, Homero. Milongas de fohn Moreyra. Buenos

Aires: Freeland, 1968. Impreso.

French, Alfredo Mario. Fuan Moreyra, poema teatral en tres

actos. La Plata: Olivieri y Domínguez, 1923. Impreso. 
García Satur, Enrique y Amando Villador. Arreando ensueños. Buenos Aires: Buchieri, 1959. (Contiene "Juan Moreira: leyenda épica" de Villador). Impreso.

Ghiano, Juan Carlos (ed.). El Amor de la estanciera. El detalle de la acción de Maipú. Las bodas de Chivico y Pancha. Fuan Moreira. Buenos Aires: Losange, 1957. Impreso.

Gutiérrez, Eduardo. Fuan Moreira. Buenos Aires: La Patria Argentina, 1880.

(Otras eds. Buenos Aires: Luis Maucci y Cía., 1891; Buenos Aires: N.

Tommasi, s.f.; Buenos Aires: El Boyero, 1951; Buenos Aires: Tor, 1951;

Buenos Aires: Losange, 1957; Rosario: Ed. Biblioteca, 1968; Buenos Aires:

Eudeba, 1961 y 2012; Buenos Aires: CEAL, 1980, 1987 y 1993; Buenos Aires:

Perfil Libros, 1999; Buenos Aires: Longseller, 2006 y 2010). Impreso.

Gutiérrez, Eduardo. Fuan Moreira: obra gauchesca en tres actos. Buenos Aires: Prensa Moderna, s.f. Impreso.

Gutiérrez, Eduardo. La muerte de fuan Moreira. Buenos Aires:

La Tradición Americana, s.f. (década de 1930). Impreso.

Gutiérrez, Eduardo y José J. Podestá. Fuan Moreira: drama. Buenos

Aires: Coni, 1935. (Otra ed. Buenos Aires: Nova, 1944). Impreso.

Gutiérrez, Ernesto. "Juan Moreira". La Escena 83 (1920). Impreso.

Hechos famosos del gaucho fuan Moreira. Buenos Aires: s.f. (c. 1919). Impreso.

Hidalgo, Félix. Los primeros amores de fuan Moreira. Buenos Aires:

El progreso literario - Marcelino Bordoy, 1894. Impreso.

Historia en verso de fuan Moreira. Buenos Aires: 1900.

(Otras 3 eds. de Bibl. Criolla, s.f.). Impreso.

Irellor, Santiago. Historia del terrible gaucho fuan Moreira, primera parte.

5ta. ed. Buenos Aires y Montevideo: S. Rolleri, 1896. Impreso.

Jasme Igneson, Eladio. Fuan Moreira en versos gauchescos. Buenos

Aires: Bibl. Gauchesca, 1896. (Otra ed. de 1904). Impreso.

fuan Moreira. Poema en versos camperos que reflejan la vida del inmortal gaucho, Buenos Aires: J. Scalogna, s.f. (imposible fechar). Impreso.

Lapeyrette, Víctor Alberto. Fuan Moreira. Luján: 1967. Impreso.

López Franco, J. Vidalitas. Buenos Aires: 1900. (Contiene

"Moreira y Sardetti", pp. 15-30). Impreso.

Manco, Silverio. Fuan Moreira. Buenos Aires: P. Mediano, s.f. (c. 1907). (Otras eds. S.l., s.e., s.f.; Buenos Aires: Buchieri, 1943. 2da. Ed. en 1944). Impreso.

Massaroli, José. ¡Juan Moreira! (historieta). Comodoro

Rivadavia: La Duendes, 2010. Impreso.

Novión, Alberto. "Doña Juana Moreira". Argentores I.2 (1934). Impreso. 
Payró, Roberto. Divertidas aventuras del nieto de fuan Moreira, Buenos Aires, 1910. (Otras eds. Buenos Aires: Losada, 1939, 1944, 1957, 1967, 1971 y 1991; Buenos Aires: Colihue, 1981 y 1992; Buenos Aires: CEAL, 1991). Impreso.

Pérez Cuberes, Andrés. Fuan Moreira: leyenda gaucha.

Buenos Aires: Pérez, s.f. (c. 1910). Impreso.

Retta, Vicente G. y Viale Paz. "San Juan Moreira". Bambalinas 539 (1928). Impreso.

Rojas, Nerio. El verdadero fuan Moreira. Buenos Aires: 1943. Impreso.

Saldías, José Antonio. "Jesús Moreira". Bambalinas 300 (1924). Impreso.

Sanguinetti, Orlando. Fuan Moreira y el Sargento

Chirino. Saladillo: Las Noticias, 1934.

Sierra, A. Fuan Moreira. Buenos Aires: Colección Gaucha, s.f. (c. 1945). Impreso.

Sierra, Apolinario. Fuan Moreira. Buenos Aires: Caymi, 1959. Impreso.

Sierra, Apolinario. La muerte de fuan Moreira. Buenos Aires: Caymi, 1957. Impreso.

Soiza Reilly, Juan José de. "Juan Moreira está vivo".

La Novela Semanal 572 (1928). Impreso.

Vaccarezza, Alberto. "Juan Moreira". La Escena 272 (1923). Impreso.

Villador, Amando. Fuan Moreira: poema épico. Buenos

Aires: Buchieri, 1949. Impreso.

\section{JUAN SIN PATRIA (JP)}

Alma Nativa. Fuan sin Patria y Hormiga Negra. S.l., s.f. Impreso.

Braña, José M. Fuan sin Patria. Rosario: Longo y Argento, s.f. Impreso.

Cientofante, Manuel. Fuan sin patria, el gaucho relámpago. Buenos

Aires: Salvador Matera, 1900. (Otra ed. de 1906). Impreso.

Gutiérrez, Eduardo. Fuan Sin Patria. Buenos Aires: La Patria Argentina, 1881. (Otra ed. Buenos Aires: N. Tommasi, s.f.). Impreso.

Jasme Igneson, Eladio. Fuan Sin Patria en versos gauchescos.

Buenos Aires: Imprenta de las Provincias, 1894. (Otra ed.

Buenos Aires: Bibl. Gauchesca, 1905). Impreso.

Manco, Silverio. Fuan sin Patria. Buenos Aires: Bibl. Criolla, s.f. Impreso.

\section{JUAN SOLDAO (JS)}

Abaca, Hilarión. Fuan Soldao. Rosario: s.f. Impreso.

Irellor, Santiago. El gaucho Feliciano López en la representación

del drama fuan Soldao, primera parte. 3ra. ed. Buenos

Aires - Montevideo: S. Rolleri, 1903. Impreso.

Fuan Soldao. Buenos Aires: Salvador Matera - Bibl. Criolla, 1905. Impreso. 
Fuan Soldao, cuentos folklóricos de la Argentina.

Buenos Aires: Eudeba, 1962. Impreso.

Roberto, Germán. Fuan Soldao. Rosario: Longo y Argento, s.f. Impreso.

Vida del famoso gaucho oriental fuan Soldao. Buenos Aires:

Bibl. Criolla - Salvador Matera, 1901. Impreso.

\section{JUAN VALIENTE (JV)}

Cientofante, Manuel. El gaucho fuan Valiente, o sea el tenorio del amor. Buenos Aires: Andrés Pérez, 1902. Impreso.

En catálogo. Fuan Valiente. Rosario: Longo y Argento, s.f. Impreso.

fuan Valiente, tenorio del Tandil. Buenos Aires: Bibl. Gauchesca, 1905. Impreso.

Rolleri, Santiago. El gaucho fuan Valiente, 2 vols. Buenos Aires y

Montevideo: S. Rolleri, 1901. (Otra ed. de 1903). Impreso.

Rolleri, Santiago. La desesperación y muerte del gaucho fuan Valiente. 3ra. ed.

Buenos Aires - Montevideo, S. Rolleri, 1897. (4ta. ed. de 1900). Impreso.

\section{JULIÁN JIMÉNEZ (o GIMÉNEZ) (JJ)}

Abaca, Hilarión. Fulián Gimenez, 3ra. ed. Rosario: Alfonso Longo, s.f. Impreso.

Aprile, Bartolomé. Fulián Gimenez. Buenos Aires: Alfredo

Angulo - Colecciones Gauchas, 1935. Impreso.

Cientofante, Manuel. Vida y muerte del valiente gaucho oriental fulián fiménez.

Buenos Aires: Salvador Matera, 1900. (Otra ed. de 1906). Impreso.

Hidalgo, Félix. Fulián Gimenez. Buenos Aires: Bibl. Gauchesca, 1900. Impreso.

Serafín el Diablo. Fulián Gimenez o el gaucho oriental.

Rosario: Longo y Argento, s.f. Impreso.

\section{MARTIN FIERRO (MF) y derivados}

Albarracín, Policarpo. El hijo de Martín Fierro, primera parte.

Rosario: Longo y Argento, s/f. (c. 1914). Impreso.

Aprile, Bartolomé. El hijo de Martín Fierro. Buenos Aires: Peuser, 1933. Impreso.

Barrios, Evaristo. La guitarra de Martín Fierro.

Buenos Aires: Buchieri, 1947. Impreso.

Berón, Sebastián C. La muerte de Martín Fierro. Truco y retruco. El

gaucho Pancho Bravo. Buenos Aires: Buchieri, 1948. Impreso.

Borghese, Juan. Página criolla. Historia del gaucho Floriano Montiel, nieto de Martín Fierro. S.l., s.f. (posiblemente Angulo, c. 1940). Impreso.

Castellani. La muerte de Martín Fierro. Buenos Aires: Cintra, 1953. Impreso. 
Cientofante, Manuel. El hijo de Martín Fierro. Buenos Aires:

Francisco Matera - Bibl. Gauchesca, 1909. Impreso.

Cientofante, Manuel. Martín Fierro. Buenos Aires: Andrés Pérez, s.f. Impreso.

Díaz, Francisco. Un nieto de Martín Fierro y otros versos. Buenos Aires: Talleres

Gráficos "Contreras", 1945. (Otra ed. Buenos Aires: Dunken, 1994). Impreso.

El hijo de Martín Fierro. Buenos Aires: Bibl. Criolla

- Salvador Matera, 1910. Impreso.

González Castillo, José. Martín Fierro, inmortal poema gaucho teatralizado con sujeción estricta al original, en verso. Buenos Aires:

El Teatro Nacional, 1918. (Otra ed. Argentores, n. ${ }^{\circ}$ 199, 1941; Buenos

Aires: Instituto Nac. de Estudios de Teatro, 1942). Impreso.

Hernández, José. El Gaucho Martín Fierro. Buenos Aires:

Imprenta de La Pampa, 1872. (Innumerables ediciones de esta y de la segunda parte aparecida en 1879). Impreso.

Hernández, José. Los consejos del Viejo Vizcacha del libro Martín

Fierro. Buenos Aires: Gobbi y Cía., s.f. Impreso.

Hernández, José. Martín Fierro. Consejos del Viejo Vizcacha, Buenos Aires: Peuser S.A., 1945. Impreso.

Irellor, Santiago. El hijo de Martín Fierro. 7 ma. ed. Buenos

Aires - Montevideo: S. Rolleri, 1900. Impreso.

Irellor, Santiago. Historia completa del gaucho Martín Fierro

y de su amigo Cruz. 1ra. ed. Buenos Aires - Montevideo:

Santiago Rolleri, 1902. (4ta. ed. de 1908). Impreso.

Irellor, Santiago. Nuevo gaucho Martín Fierro. 2da. ed. Buenos

Aires - Montevideo: S. Rolleri, 190o. Impreso.

Jasme Igneson, Eladio. Martín Fierro. Buenos Aires: Bibl.

Gauchesca, 1900. (Otras eds.: s.f., 1896 y 1901). Impreso.

Magliole Jaimes, Pedro. Martín Pueblo. Buenos Aires:

Mundo Peronista, 1952. Impreso.

Manco, Silverio. El hijo de Martín Fierro. Rosario: Longo y Argento, 1920. (Otra

ed.: Buenos Aires: ¿Angulo?, 1943; Buenos Aires: Caymi, 1957). Impreso.

Manco, Silverio. Martín Fierro. Rosario: Longo y

Argento, s.f. (Al menos 5 eds.). Impreso.

Manso, Severo. La mujer de Martín Fierro. Buenos Aires:

Sabourin e Hijo, s.f. (c. 1916). Impreso.

Martín Fierro. Buenos Aires: Bibl. Criolla - Salvador Matera, 1909. Impreso.

Martín Fierro. Adaptación de Héctor Sánchez Puyol; Ilustr. de

Eleodoro Marenco. Buenos Aires: Codex, 1949. Impreso. 
O'Trebor, Juan. Martín Fierro, obra adaptada para los niños, con ilustraciones en color. Buenos Aires: Laud, 1939. Impreso.

Pérez Carabajal, Gregorio. El nieto de Martín Fierro. Buenos Aires: Tall. Gráf. A.B.C., 1951. Impreso.

Roberto, Germán. El gaucho Martín Fierro: verdadera historia. Rosario: Longo y Argento, s.f. Impreso.

Sallot, Juan Eugenio. El hijo de Martín Fierro. Buenos Aires: Vicente Matera - Bibl. Criolla, s.f. Impreso.

Terza, José Elías. Vida de Facinto Martín Fierro, el hijo de Martín Fierro. Buenos Aires: Min. de Cultura y Educación, 1972. Impreso.

Villador, Amando. Las glorias de Martín Fierro. Buenos Aires: Buchieri, 1946. Impreso.

Villador, Amando. Los hijos de Martín Fierro. Buenos Aires: 1945. Impreso. Zavattaro, Mario. Martín Fierro: escenas ilustradas. Buenos

Aires: Fábrica Argentina de Alpargatas, 1937. Impreso.

\section{PAJA BRAVA (PJ)}

Abaca, Hilarión. Paja Brava. 3ra. ed. Rosario: Alfonso Longo, s.f. Impreso. Alonso y Trelles, José. Paja Brava. 4ta. ed. aumentada, Montevideo - Buenos Aires: Agencia Gral. de Librería, 1926. (Primera ed. es de 1915). (Otras eds. Buenos Aires: Claridad, 1925 y 1936; Buenos Aires: Apolo, s.f. [c. 1926]; Buenos Aires: Bibl. de Grandes Obras, 1937). Impreso.

Caro, A. El gaucho Paja Brava. Rosario: Longo y Argento, s.f. Impreso.

El Viejo Pancho (pseud. de J. Alonso y Trelles). Paja brava: versos criollos, Montevideo - Buenos Aires: Palacio del libro, 1929. (6ta. ed. 1930). (Otras eds.: Buenos Aires: [¿Buchieri?], 1941; Buenos Aires: Tor, 1950). Impreso.

\section{PANCHO BRAVO (PB) y secuelas}

Berón, Sebastián C. El gaucho Pancho Bravo, segunda parte. 8va. ed. Buenos Aires: Llambías, 1895. Impreso.

Berón, Sebastián C. El hijo de Pancho Bravo, 2 vols. 2da. ed. Buenos Aires: Llambías, 1898. (Hay una ed. del autor de 1887). Impreso.

Berón, Sebastián C. La muerte de Martín Fierro. Truco y retruco. El gaucho Pancho Bravo. Buenos Aires: Buchieri, 1948. Impreso.

Cientofante, Manuel. El hijo de Pancho Bravo. Buenos Aires:

Francisco Matera - Bibl. Campera, 1909. Impreso.

Cientofante, Manuel. Pancho Bravo. Buenos Aires: F.

Matera - Bibl. Campera, 1909. Impreso. 
En Catálogo. El gaucho Pancho Bravo. Rosario: Longo y Argento, s.f. Impreso.

En Catálogo. El hijo de Pancho Bravo. Rosario: Longo y Argento, s.f. Impreso.

Irellor, Santiago. El terrible gaucho Bravo, ira. ed. Buenos

Aires - Montevideo: S. Rolleri, 1903. Impreso.

\section{PASTOR LUNA y secuelas (PL)}

Abaca, Hilarión. La venganza del Mataco. $4^{\text {ta }}$ ed.

Rosario: Alfonso Longo, s.f. Impreso.

Abaca, Hilarión. Pastor Luna. Rosario: Longo y Argento, 1919. (5ta. ed. de Alfonso Longo, s.f.). Impreso.

Alma Nativa (S.M.). El Mataco y El Chacho. S.l., s.f. Impreso.

Aprile, Bartolomé. La venganza del Mataco. Buenos

Aires: Colecciones Gauchas, 1937. Impreso.

Aprile, Bartolomé. Pastor Luna. Buenos Aires: A. Angulo, 1935. Impreso.

Bosque, Horacio del. Pastor Luna. Buenos Aires: Andrés Pérez, 1900.

(Otra ed. Rosario: Longo y Argento, s.f. [previo a 1913]. Impreso.

Cientofante, Manuel. ¡La muerte del Mataco! Buenos Aires:

Salvador Matera, 1902. (Otras eds. 1905 y 1910). Impreso.

El traicionero López y la venganza del Mataco. Buenos Aires:

Bibl. Criolla - Salvador Matera, 1900. Impreso.

Gutiérrez, Eduardo. El Mataco. Buenos Aires: Maucci, 1895 .

(Otras eds. Buenos Aires: Rovira, 1932). Impreso.

Gutiérrez, Eduardo. Pastor Luna. Buenos Aires: Tommasi, s.f. (Otras eds.

Buenos Aires: Luis Maucci, 1892; Buenos Aires: Rovira, 1932). Impreso.

Hidalgo, Félix. Pastor Luna. Buenos Aires: Imprenta de las

Provincias, 1894. (Otras eds. Buenos Aires: Bibl. Gauchesca, 1900;

Rosario: Longo y Argento, s.f. [previo a 1913]). Impreso.

Pastor Luna. Buenos Aires: Salvador Matera, 3ra. ed. Buenos Aires:

Bibl. Criolla - Salvador Matera, 1905. (4ta. ed. 1907). Impreso.

Pérez Cuberes, Andrés. Pastor Luna. Buenos Aires:

A. Pérez Cuberes, 1947. Impreso.

Roberto, Germán. La venganza del Mataco. Rosario: Longo y Argento, s.f. Impreso.

Roberto, Germán. Pastor Luna. Rosario: Longo y Argento, s.f. Impreso.

Salto, Luis J. del. El paisano Pastor Luna. Buenos Aires: 1902. Impreso.

Sierra, A. La venganza del Mataco. Buenos Aires:

Colecciones Gauchas, s.f. (c. 1945). Impreso.

Villador, Amando. Pastor Luna. Buenos Aires: Buchieri, 1946. Impreso. 


\section{PRUDENCIO TRANQUERA (PT)}

Alma Nativa. Tranquera y Venganza. S.l., s.f. Impreso.

Cientofante, Manuel. Tranquera. Buenos Aires: Francisco

Matera - Bibl. Campera, 1908. Impreso.

Fontanella, Agustín. Tranquera, drama criollo. Buenos

Aires: N. Tommasi, 1898. Impreso.

Manco, Silverio. El gaucho tranquera. Rosario: Longo y Argento, 1921.

(Hay una ed. anterior a 1913). (2da. ed. de Alfonso Longo). Impreso.

Pastor del Cerro. El gaucho Tranquera. Rosario: Longo y Argento, s.f. Impreso.

\section{SANTOS VEGA y secuelas (SV)}

Abaca, Hilarión. La muerte de Carmona (Una amistad hasta la muerte). Rosario: Longo y Argento, s.f. Impreso.

Albarracín, Policarpo. Santos Vega, primera parte. Rosario: Longo y Argento, s.f. (1914). (Otra ed. de 1919 firmada por Hilarión Abaca, con 7 eds. por Alfonso Longo). Impreso.

Albarracín, Policarpo. Una amistad hasta la muerte. Rosario: Longo y Argento, s.f. (c. 1914). Impreso.

Aprile, Bartolomé. Carmona. S.l.: Buchieri?, s.f. Impreso.

Aprile, Bartolomé. Santos Vega. Buenos Aires: Colecciones Gauchas, 1935. Impreso.

Aprile, Bartolomé. Una amistad hasta la muerte. Buenos Aires:

Librería Roma - Colecciones gauchas, s.f. Impreso.

Ascasubi, Hilario. Santos Vega o los mellizos de la flor. París: Imprenta de

Paul Dupont, 1872. (Otras eds. Buenos Aires: Peuser, 1898; Buenos

Aires: Casa Vaccaro, 1919; Buenos Aires: Sopena, 1939; 4ta ed.

Buenos Aires: Jackson, 1946; varias eds. posteriores). Impreso.

Bayón Herrera, Luis. Santos Vega, Buenos Aires: F. Hostench, 1916. Impreso.

Bayón Herrera. Luis. "Santos Vega". La Escena 96 (1920). Impreso.

Bellazzi, Luis de. Santos Vega, el payador. 2da. ed. Buenos

Aires: Andrés Pérez, 1930. Impreso.

Bernárdez Jacques, Elbio. La tumba de Santos Vega. Buenos Aires: 1947. Impreso.

Berón, Sebastián C. Santos Vega. gna. ed. Buenos Aires: Bibl.

Gauchesca, 1900. (Hay otras dos eds. posteriores). Impreso.

Bosque, Horacio del. Los cantos de Santos Vega y su amistad con Carmona, segunda parte. Buenos Aires: Andrés Pérez, 1898. Impreso.

Bosque, Horacio del. Santos Vega, primera parte. Buenos Aires:

Andrés Pérez, 1898. (Otra ed. 1902). Impreso. 
Gutiérrez, Eduardo. Santos Vega. Buenos Aires: La Patria Argentina, 1880. (Otras eds.: Buenos Aires: P. Buffet, 1886; Buenos Aires: El Boyero, 1951; Buenos Aires: Lumen, 1952). Impreso.

Gutiérrez, Eduardo. Una amistad hasta la muerte. Buenos Aires: Tommasi, s.f. (Otras eds. Buenos Aires: Luis Maucci, 1891 y 1896; Buenos Aires: Rovira, 1932; Buenos Aires: Lumen, 1952). Impreso.

Manco, Silverio. Santos Vega. Buenos Aires: Bibl. Criolla, s.f. (otra ed. Buenos Aires: Buchieri, 1943). Impreso.

Martín Zorrilla, Reginaldo. La revancha de Santos Vega: Trenzado lírico. Buenos Aires: Bartolomé U. Chiesino, 1951. Impreso.

Obligado, Rafael. Santos Vega. Buenos Aires: Ediciones mínimas, 1917. (Otras eds. Santa Fe: Castellví, s.f. [ post. 1932]; Buenos Aires: Sociedad Amigos de Rafael Obligado, 1937; varias eds. posteriores). Impreso.

Pagés Larraya, Antonio. Santos Vega: el payador: leyenda trágica en un preludio y tres actos. Buenos Aires: Doble P, 1953. (Otra ed. Buenos Aires: Sociedad General de Autores de la Argentina, 1965). Impreso.

Pérez Cuberes, Andrés. Santos Vega el payador. Buenos

Aires: Andrés Pérez Cuberes, 1947. Impreso.

Rodríguez Morel, J. R. El payador Santos Vega. Buenos Aires: 1944. Impreso.

Sallot, J. Eugenio. Santos Vega. S.l., s.f. Impreso.

Villador, Amando. Santos Vega. Buenos Aires: Buchieri, 1946. Impreso.

\section{EL TIGRE DE QUEQUÉN (TQ)}

Abaca, Hilarión. El Tigre de Quequén. Rosario: Longo y Argento, s.f. (c. 1920). (Otra ed. de Alfonso Longo). Impreso.

Aprile, Bartolomé. El Tigre del Quequén. Buenos Aires: A. Angulo, 1935.

(Otra ed. Buenos Aires: Publicidad "Ateneo", 1941). Impreso.

Gutiérrez, Eduardo. El Tigre del Quequén. Buenos Aires: La

Patria Argentina, 188o. (Otras eds. Buenos Aires: Tommasi,

s.f.; Buenos Aires: Luis Maucci, 1895). Impreso.

Hidalgo, Félix. El Tigre del Quequén. Buenos Aires:

El Progreso Literario, 1894. Impreso.

Jasme Igneson, Eladio. El Tigre de Quequén. Buenos Aires: Bibl.

Gauchesca, 1897. (Otras eds. de 1900 y 1904). Impreso.

\section{[T2]EL TIGRE DEL DESIERTO (TD)}

Aguirre, R. El Tigre del desierto. Rosario: Alfonso Longo, s.f. (Hay una 3ra. ed. s.f. y una ed. de Longo y Argento anterior a 1913). Impreso. 
Alma Nativa. El Tigre del Desierto y Los Montoneros. S.l., s.f. Impreso.

Berón, Sebastián C. El Tigre del Desierto, primera parte. 8va ed.

Buenos Aires: Llambías, 1898. (Otra ed. de 1895). Impreso.

Cientofante, Manuel. El Tigre del desierto. Buenos Aires:

Francisco Matera - Bibl. Campera, 1909. Impreso.

\section{LOS TRES GAUCHOS ORIENTALES (GO)}

En Catálogo. Los tres gauchos orientales. Rosario: Longo

y Argento, s.f. (Anterior a 1913). Impreso.

Hidalgo, Félix. Los tres gauchos orientales. Buenos Aires: Bibl.

Gauchesca, 1896. (Otra ed. de 1904). Impreso.

Los tres gauchos orientales. Buenos Aires: Bibl. Criolla

- Salvador Matera, 1906. Impreso.

Lussich, Antonio D. El matrero Luciano Santos: prosecución de los tres

gauchos orientales. Buenos Aires: Comercio, 1873. Impreso.

Lussich, Antonio D. Los tres gauchos orientales. Buenos Aires: Imprenta de

"La Tribuna", 1872. (Otra ed. Buenos Aires: Buchieri, 1946). Impreso.

\section{OTROS PERSONAJES (OT)}

Acosta, Luis. El gaucho Gato Moro. Buenos Aires: Colección

Gaucha - Bibl. Nueva, 1947. Impreso.

Albarracín, Policarpo. El gaucho Buenaventura.

Rosario: Longo y Argento, s.f. Impreso.

Alma Nativa. El gaucho de la frontera; fusticia! Buenos

Aires: Andrés Pérez, s.f. Impreso.

Alma Nativa. Tranquera y Venganza. S.l., s.f. Impreso.

Aprile, Bartolomé. El gaucho Cipriano Cielo. Buenos Aires:

A. Angulo - Colecciones Gauchas, 1935. Impreso.

Aprile, Bartolomé. El matrero Amarga Flor. Buenos Aires: A.

Angulo - Colecciones Gauchas, 1936. Impreso.

Aprile, Bartolomé. El viejo Cruz de los llanos. Buenos

Aires: Colecciones Gauchas, 1936. Impreso.

Aprile, Bartolomé. La gaucha Vicenta. Buenos Aires:

Colecciones Gauchas, s.f. Impreso.

Aprile, Bartolomé. Martín Laguna. Buenos Aires:

Colecciones Gauchas, 1947. Impreso.

Barrios, Evaristo. Santiago Miranda. Buenos Aires: Colección Gaucha,

c. 1946. (Otra ed. Buenos Aires: Caymi, 1957). Impreso. 
Berón, Sebastián C. Lucas Barrientos (gaucho de corazón). Buenos Aires: Bibl.

Gauchesca, s.f. (Otra ed. Rosario: Longo y Argento, s.f.). Impreso.

Castro, M. El gaucho Lisandro Cruz. Buenos Aires: Buchieri, 1944. Impreso.

Castro, Martín. Los gringos del país. Buenos Aires: Colecciones gauchas - Angulo: s.f. (c. 1937). Impreso.

Cientofante, Manuel. El gaucho maldito. Buenos Aires: s.f. Impreso.

Cobos, Roldán. Romance del gaucho Sombra. Buenos Aires: Buchieri, 1944. Impreso.

Díaz, Faustino V. El payador porteño. El gaucho fuan Mauricio, sus amores, su vida. Buenos Aires: Bibl. Poética Argentina, 1896. Impreso.

En Catálogo. El gaucho maldito, o sea fuan Aldao. Rosario: Longo y Argento, s.f. (Anterior a 1913). Impreso.

Flores de los Llanos, Manuel. El gaucho oriental. Rosario: Alfonso Longo, s.f. Impreso.

García, L. A. El matrero Cruz Montiel. Buenos Aires: Buchieri, 1944. Impreso. Hidalgo, Félix. El Tigrero, capitán de los bandidos de las Sierras del Cristiano. Buenos Aires: Bibl. Gauchesca, 1895. Impreso.

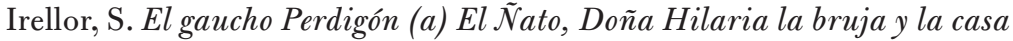
encantada. 1ra ed. Buenos Aires - Montevideo: Santiago Rolleri, 1903. Impreso.

Iturriaga y López, Ramón de. El rescate de la cautiva. ̧ra. ed. Buenos Aires: José Bosch, s.f. (Es la segunda parte de La venganza de un gaucho). Impreso.

Iturriaga y López, Ramón de. Fuan Guardia. 2da. ed. Buenos Aires: José Bosch, 1889. Impreso.

Iturriaga y López, Ramón de. La venganza de un gaucho. 4 ta. ed. Buenos Aires: José Bosch, 189o. Impreso.

Iturriaga y López, Ramón de. Matías el domador. Buenos Aires: José Bosch, s.f. (c. 1892). Impreso.

Jasme Igneson, Eladio. El gaucho del Pilar. Buenos Aires: La Americana, 1893. Impreso.

fuan Macana. Buenos Aires: Bibl. Criolla - Salvador Matera, 1908. Impreso. La vida de fuan Macana. Rosario: Longo y Argento, s.f. Impreso.

López Franco, J. La vida de fuan Macana. Buenos Aires: 1899. (Otra ed. de 1905). Impreso.

Manco, Silverio. El gaucho picaflor. Rosario: Longo y Argento, 1921. (Otra ed. anterior a 1913). Impreso.

Manco, Silverio. El rebenque fatal. Buenos Aires: Buchieri, 1945. Impreso.

Manco, Silverio. La tropilla de la muerte. Buenos Aires: Buchieri, 1942. Impreso.

Manco, Silverio. Venganza gaucha. Buenos Aires: Buchieri, 1943. Impreso.

Marcó, Héctor. La güelta'e Cipriano. Buenos Aires: Buchieri, 1946. Impreso. 
Medina, Floreal. El desafío gaucho. Buenos Aires: Buchieri, 1944. Impreso.

Monroy, F. C. El gaucho de las fronteras. Suspiros de amor.

Finalizando con la popular canción del Caramelo. Buenos

Aires - Montevideo: Santiago Rolleri, 1888. Impreso.

Monty Luro, Juan María. El gaucho Floro Corrales.

Buenos Aires: Kraft, 1949. Impreso.

Páez, Aníbal Rafael. La historia de Lucero Moya. 3 ra

ed. Buenos Aires: 1956. Impreso.

Togenar, Talvi. El gaucho Horacio Cruz, el buen paisano

oriental. Rosario: Longo y Argento, s.f. Impreso. 